\title{
Air transport of patients with critical cardiac conditions requiring intensive care
}

\author{
Özgür Kırbaş $®$
}

Department of Cardiology, Faculty of Medicine, Lokman Hekim University; Ankara-Turkey

\section{ABSTRACT}

It is extremely important that patients with severe heart disease who need an intensive care unit can be quickly transferred to advanced centers. Air transport is the fastest and safest way for doing this in these patients, and its importance has been recognized in recent years. In this review, we examined the details of air transport of patients with critical cardiac conditions.

Keywords: air transport of ill patients, intensive care in aeromedical transport, physiological effects of air transport

\section{Introduction}

Aeromedical transport of critical patients by plane and helicopter has been happening for nearly 80 years. In the 1990 s, the Turkish military forces began aeromedical transport. Air medical transport of patients by the civil airlines in Turkey started in 2000 and is developing fast (1). From 2008 to 2019, 45,363 patients have been transported by air ambulances. An ambulance aircraft carrying intensive care equipment is currently in service in Turkey (2).

The concept of a critical care air transport team was developed by the U.S. Air Force in the 1988. Currently, it comprises teams of specialists in critical care, emergency medicine, anesthesiology, and surgery with support staff trained in critical care who operate a portable ICU on a transport aircraft (3).

Aeromedical transport can be done in different ways according to the need. The patients can be moved from the scene of an incident to the most suitable center (primary transfer), between medical facilities for specialist services (secondary transfer), or across international borders for repatriation. Elective long-distance transport of patients in unstable condition (patients who need a mechanical ventilator, IV vasopressors, or antiarrhythmic drugs) and emergency long-distance transport is performed using fixed-wing air ambulances (4).

\section{Physiological effects and solutions of air transfer}

\section{Atmospheric pressure}

Atmospheric pressure progressively decreases with alti- tude. Consequently, the partial pressure of inspired oxygen decreases proportionally with increasing altitude, which can lead to hypoxia. Systemic hypoxia is primarily compensated by chemoreceptor-mediated hyperventilation and tachycardiamediated increased cardiac output. Hypoxia can also cause ventricular arrhythmias, hypotension, myocardial ischemia, and behavioral changes. If the patient becomes hypoxic during flight, this can be corrected with either an increase in the inspired oxygen concentration or increasing the atmospheric pressure by reducing the altitude of flight or pressuring the cabin to a lower altitude. Consideration should be given to patients with cardiac failure, congenital heart disease with right to left shunting, and pulmonary disorders, as the relative hypoxia at altitude will result in a lower partial pressure of oxygen in the arterial blood in this patient group (5-7).

\section{Volume expansion}

The volume of gas in enclosed spaces increases with a drop in atmospheric pressure. This gas expansion as the aircraft ascends to a higher altitude has the potential to cause a pneumothorax (5). If patients have a pneumothorax, they should be ventilated, and a chest drain placed before air transfer to prevent an increase in the size of the pneumothorax. Attention should be paid to patients with intestinal obstruction, and their transfers should be performed by flying at low altitude. Equipment with air-blown cuffs, such as endotracheal tubes, SengstakenBlakemore tubes, and stoma bags should have their pressures monitored. Because of the volume expansion at ascent, cuff

Address for Correspondence: Dr. Özgür Kırbaş, Department of Cardiology,

Faculty of Medicine, Lokman Hekim University; Ankara-Turkey

Phone: +90 5068601380 E-mail: ozgurkirbas@yahoo.com 
pressure will rise, and the volume of air in the cuff will need to be reduced to maintain an appropriate pressure. On descent, additional air will need to be added to the cuffs. An alternative option is to fill the endotracheal cuff with isotonic solution. Liquid expands much less than air (6).

\section{Temperature}

The temperature drops by $2^{\circ} \mathrm{C}$ for every 1,000 feet increase. Although not expected in modern aircrafts, patients being transported at high altitudes without isolated cabins for long periods are at risk of hypothermia $(5,7)$.

\section{Humidity}

Dehydration occurs faster at higher altitudes owing to lower air pressure and humidity, which causes rapid evaporation of moisture from the skin and lungs. Patients with cardiac failure, on diuretics and undergoing long transfers should be closely monitored to avoid hypovolemia and dehydration. Reduced humidity can lead to thickened secretions and risk of mucous plugging, and therefore, a heat moisture exchange filter or humidified oxygen via a facemask should be used. For extended transfers, the patient's eyes should be lubricated with artificial tears, and frequent mouth care is important $(5,7)$.

\section{Noise and vibration}

The noise and vibrations, especially in a helicopter, can be a trigger for conscious patients, especially if there is an element of delirium. They should be provided with ear protection or a headset. Vibration can affect monitoring equipment such as non-invasive blood pressure cuffs, and patients who require accurate blood pressure monitoring should, therefore, have an arterial line inserted prior to transfer to allow for accurate blood pressure monitoring during flights $(5,7)$.

\section{Limited space}

Space is limited in helicopters than in land ambulances making intubation extremely difficult in a helicopter. Therefore, all the patients at risk of deterioration should be evaluated for intubation before the transfer $(5,7)$.

\section{Indications}

Aeromedical transport is expensive and potentially problematic (to the patient and the team) and should not be undertaken unless absolutely necessary. For example, transporting a patient with chronic coronary syndrome in a hypoxic environment is a potentially dangerous condition that requires rigorous patient selection. In addition, unsafe patients (those with confusion, psychosis, or prone to violence), terminally ill patients, patients already in cardiac arrest, or those likely to die during transport are unlikely to benefit.

Rapid transfer needed for definitive care is an important indication for an aeromedical transfer. If personnel or equipment needs of the patient cannot be met by the local centers, transfer to an intensive care unit might be appropriate. Helicopters vary in size, accommodation, and range. They generally provide a less comfort- able and more cramped environment than a pressurized fixedwing aircraft. Therefore, it should not be the primary consideration in critically ill patients who need intensive care. Fixed wing aircrafts are typically considered for transfer distances greater than $240.000 \mathrm{~m}(8)$.

\section{Equipment and crew}

Air ambulances carrying patients with critical cardiac conditions should be organized to function as flying intensive care units with a full range of drugs and portable equipment, including IV drug pumps, cardiac monitor, defibrillator, ventilator, pulse oximetry, and blood gas analyzer. Equipment that can be used safely in an aircraft and transported when necessary should be available. Space saving backpacks are often used to carry equipment, and paramedics should be familiar with their content. Potential difficulties with equipment should be identified and foreseen to be able to deal with them. For example, mechanical IV infusion pumps may be required for long flights. Long battery life is important, even though most aircrafts are powered. Battery life must be checked before the flight. It is necessary to carry spare equipment to guard against equipment failure. However, aircraft weight should also be considered. Routine and emergency medicines required for the patient should be checked before departure. A medical crew consisting of an intensive care trained physician, nurse, and/or paramedic are necessary for such transfers (8).

\section{Oxygen}

Oxygen must be available for transfer to and from the aircraft. In-built oxygen is generally the responsibility of the pilot, but paramedics should ensure that they are adequate and open. There are 2 modes of additional oxygen delivery that can be requested onboard: continuous flow and trigger controlled. Continuous-flow regulators usually offer predefined free flows of 2 and $4 \mathrm{~L} / \mathrm{min}$ on specific connectors. A portable cylinder will be required to transfer to and from the aircraft, and spare oxygen must be present in case of unexpected delays. There are several sizes of tanks, from portable cylinders up to a maximum of 3,200 L. These tanks require an attachment for the fixing rails on the cabin floor. There is also a specific three-pin quickrelease connector to allow the connection of a ventilator $(8,9)$.

\section{Special cases}

A significant proportion of patients transferred by air ambulances are patients with acute myocardial infarction (MI). In a significant percentage of acute $\mathrm{Ml}$ conditions, there may be an urgent need for implantation of a temporary pacemaker. Hence, temporary pacemaker sets must be available in the air ambulance (10). The function of implantable automatic defibrillators used in the treatment of recurrent ventricular arrhythmias during air travel is controversial. It should also be noted that these can be affected by vibrations of the aircraft engine and can cause false shocks (11).

Intra-aortic balloon pumps are very important for treating patients in cardiogenic shock awaiting definitive therapy. Safe 
air transport of these devices has been confirmed mostly in the transfer of patients from rural centers to tertiary care centers. However, the effects of the expansion of gases at high altitudes on the function and size of the inflated balloon must be considered. Intra-aortic pressure should be equalized at every 1,000 feet of ascent to maintain constant volume (recommended according to the results of laboratory studies) (11). Transporting patients with critical cardiac conditions with cardiopulmonary support devices is the final point of aeromedical transport. The first reported transfer of a patient with an extracorporeal left ventricular assist device occurred in 1992. More recently, recipients of the Novacor left ventricular assist system (World Health Corporation; Ottawa, ON, Canada) were reported to have undergone more than 37 air transports throughout Europe without incident (12).

Current guidelines on long distance flights and heart disease are limited to commercial air travel. The American College of Cardiology recommends that stable patients can travel by air within the first 2 weeks following uncomplicated MI. Patients who are unstable, symptomatic, or experiencing complicated MI (requiring CPR, developing hypotension, arrhythmia, or heart failure) are advised to wait at least 2 weeks after stabilization before commercial air travel (13). Commercial airline flights are contraindicated for 3 weeks after an uncomplicated MI, 6 weeks after a complicated MI, 2 weeks after a coronary artery bypass surgery, and 2 weeks after a cerebrovascular accident according to the Aerospace Medical Association guidelines (14). However, with the presence of fixed-wing air ambulances equipped with intensive care facilities, cardiac patients are able to be transferred earlier than these recommendations (15).

\section{Conclusion}

Air transport of patients with critical cardiac problems is safe and life-saving if the abovementioned rules are followed.

Conflict of interest: None declared.

\section{References}

1. Inal M, Memiş D. Aero Medical Transfer of Critical Patients and Anesthesiology Speciality. Turkiye Klinikleri J Anest Reanim 2008; 6: 14-23.

2. Koca F. The ministry of health budget presentation report. 2020.
3. Ingalls N, Zonies D, Bailey JA, Martin KD, Iddins BO, Carlton PK, et al. A review of the first 10 years of critical care aeromedical transport during operation Iraqi freedom and operation enduring freedom: The importance of evacuation timing. JAMA Surg. 2014; 149: 807-13. [Crossref]

4. Beninati W, Meyer MT, Carter TE. The critical care air transport program. Crit Care Med 2008; 36: 370-6. [Crossref]

5. Beard L, Lax P. Physiological effects of transfer for critically ill patients. World federation of anaesthelogist. May 2016. Available from: URL: https://resources.wfsahq.org/atotw/physiologicaleffects-of-transfer-for-critically-ill-patients/

6. Essebag V, Halabi AR, Churchill-Smith M, Lutchmedial S. Air Medical Transport of Cardiac Patients. Chest 2003; 124: 1937-45. [Crossref]

7. Johnson D, Luscombe M. Aeromedical transfer of the critically ill Patient. The Intensive Care Society 2011; 12: 307-12. [Crossref]

8. Grissom TE. Critical-Care Air Transport: Patient Flight Physiology and Organizational Considerations. Aeromedical Evacuation: Management of Acute and Stabilized Patients: 2003; p.111-35. [Crossref]

9. Fromm RE Jr, Varon J. Critical care transport. Crit Care Clin 2000; 16: 695-705. [Crossref]

10. Nable JV, Brady W. In-Flight Medical Emergencies. 1st ed. Switzerland, 2018; 167-72. [Crossref]

11. Stone CK, Hunt RC, Sousa JA, Whitley TW, Thomas SH. Interhospital Transfer of Cardiac Patients: Does Air Transport Make a Difference? Air Med J 1994; 13: 159-62. [Crossref]

12. Jaynes $C L$, Blevnis G, Werman $H A$. Evaluating Interfacility Ground and Air Transport of the Critical Cardiac Patient. Air Med J 2002; 21: 37-41. [Crossref]

13. Antman EM, Anbe DT, Armstrong PW, Bates ER, Green LA, Hand M, et al.; American College of Cardiology/American Heart Association Task Force on Practice Guidelines (Writing Committee to Revise the 1999 Guidelines for the Management of Patients With Acute Myocardial Infarction). ACC/AHA guidelines for the management of patients with ST-elevation myocardial infarction--executive summary: a report of the American College of Cardiology/American Heart Association Task Force on Practice Guidelines (Writing Committee to Revise the 1999 Guidelines for the Management of Patients With Acute Myocardial Infarction). Circulation 2004; 110: 588-636. [Crossref]

14. Aerospace Medical Association Medical Guidelines Task Force. Medical Guidelines for Airline Travel, 2nd ed. Aviat Space Environ Med 2003; 74: A1-19.

15. Vijai MN, Parli R, Pathania A. Critical Care Air Transport: Experiences of a Decade. The Journal of Medical Research 2018; 4: 53-8. [Crossref] 